\title{
La individualidad y sus paradojas. Un análisis epistemológico-politico $y$ algunos ejemplos
}

\author{
Individuality and its paradoxes. \\ An epistemological-political analysis and some examples \\ Isabel G. Gamero Cabrera \\ Universidad Complutense de Madrid \\ ig.gamero@filos.ucm.es
}

DOI: https://doi.org/10.15366/bp2021.28.007

Bajo Palabra. II Época. No28. Pgs: 155-174

Orcid: http://orcid.org/ 0000-0002-6216-7119. 
Recibido: 19/09/2021

Aceptado: 12/11/2021

Este artículo ha sido posible gracias a la participación en el Proyecto de investigación "Institución y Constitución de la Individualidad: Aspectos ontológicos, sociales y de derecho"

(PID2020-117413GA-I00 /AEI /10.13039/501100011033).

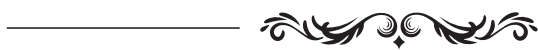

Resumen

En este artículo me propongo aclarar algunas dificultades epistemológicas y políticas del concepto de individuo. Seguiré a Joan W. Scott para argumentar que en este concepto presenta una paradoja, por ser una noción abstracta y concreta a la vez. Conectaré esa paradoja con la pregunta sobre quién es (o puede ser) considerado como individuo y sujeto de derecho y, para ello, voy a estudiar algunos usos del concepto de "individuo" en distintos escenarios y momentos de la historia europea, desde la Revolución Francesa y sus primeros debates constitucionales en torno a quién era ciudadano, hasta las consecuencias que tuvo el proceso de descolonización en Europa en el siglo XX y los debates sobre la integración de migrantes en Reino Unido. Acabaré con unas referencias sobre el ascenso de la ultraderecha y la necesidad de reivindicar un concepto de individuo, pese a todas sus dificultades y paradojas.

Palabras clave: Individualidad, Derechos Humanos, paradojas, sujeto de derecho, autonomía.

\section{Abstract}

In this paper, I am going to clarify some epistemological-political difficulties that lay under the concept of "individual". I will follow Joan W. Scott's work to argue that this concept entails a paradox, because it is abstract and particular at the same time. I will link this paradox with the question about who is (or might be) an individual and subject of law as well. To this end, I will analyse some uses of this concept in some scenarios and moments of the European History, from the revolutionary France and the first debates about who was citizen, to the consequences of the decolonial process in Europe in the $20^{\text {th }}$ Century. I will end up with some references about the rise of ultra-right parties and the necessity of claim for a concept of "individual", despite all its difficulties and paradoxes.

Keywords: individuality, Human Rights, paradoxes, subject of law, autonomy. 


\section{Delimitación conceptual y temática, ¿cómo entiendo las paradojas?}

En este artículo parto de la idea de paradoja que propone Wendy Brown (2020) en su caracterización de las dificultades que surgen al delimitar el alcance de los derechos de las mujeres, aunque me situaré en un espacio algo más amplio que el que trata Brown (daré un paso atrás, cabría decir), para preguntar ya no por los derechos de las mujeres, sino por los derechos del individuo. Esta pregunta me llevará a una delimitación del concepto de "individuo", sus dificultades y paradojas.

Para Brown, las paradojas son irresolubles. Se trata de "verdades múltiples pero inconmensurables; o una afirmación y su negación en una misma proposición" (2020:257). A diferencia de otros tropos y figuras literarias (como la contradicción o la negación) que, al ser trasladadas al debate político, se pueden resolver, disolver o incluso hacer saltar por los aires (con más o menos dificultades, mayor o menor grado de violencia...), según esta autora, "la política de la paradoja es muy difícil de negociar", ya que aparece como "continuamente autocancelatoria, como una condición política de logros perpetuamente socavados [y] un dilema del discurso en el que a cada verdad se contrapone una contraverdad" (2020:258). Esta contraposición e imposibilidad interna paraliza o congela cualquier estrategia política que esté marcada por paradojas; y conduce a lo que Wittgenstein, en otro ámbito muy distinto, definió como “callejones sin salida del filosofar" (1988:\$436). Ahora bien, en este caso, y al estar situados en la arena política y el debate sobre los derechos, estos callejones sin salida no se dan solo en un terreno filosófico, sino que nos afectan directamente a los seres humanos y nuestras vidas. Es decir, estas preguntas sobre el ser (o no ser) individuo y el tener (o no tener) derechos abren dificultades que para Joan W. Scott suponen "problemas epistemológicos que eran problemas políticos" (2012:41, cursivas de Scott).

Entiendo entonces la paradoja como una imposibilidad interna que se da dentro de un mismo término, que abre dos (o más) posibilidades que resultan incompatibles entre sí, lo que genera situaciones sin solución. Ahora bien, al menos cuando las paradojas se dan en un ámbito político, este carácter irresoluble no debería desanimarnos a la hora de abordar estas cuestiones. Justo al contrario, ante el posible derrotismo de la postura que se paraliza y sostiene que "no hay alternativas", profundizar en las paradojas, tantear sus abismos, tiene una gran potencia subversiva y sus efectos perturbadores que pueden traer cambios en la realidad. La paradoja pre- 
siona (de nuevo, de forma más o menos fácil, más o menos violenta...) para explorar regiones que nos parecían imposibles e impensadas, e inaugurar un mundo nuevo, con formas nuevas y nuevas palabras que "den sentido a nuestras acciones y pasiones", que antes no podían ser ni comprendidas ni formuladas (Birulés 2015:28). Asimismo, Brown inicia su texto sobre las paradojas recordando la "urgencia política" (2020:245) de ciertas cuestiones que se nos presentan en la actualidad. La cuestión de quién tiene derechos, ciudadanía, nacionalidad... no puede ser dejada de lado por ser paradójica o irresoluble, sino que es tarea de políticos y legisladores afrontarla y tratar de darle respuestas, que serán temporales e insuficientes, pero las necesitamos. Quizás es tarea de quienes trabajamos en filosofía aclarar las bases y presupuestos que subyacen a los conceptos paradójicos usados por políticos y legisladores. En este artículo no pretendo más que aclarar las paradojas que subyacen bajo el término "individuo", en su conexión con la posibilidad de ser (o no ser) sujeto de derecho, para posteriormente trasladar este análisis a algunos escenarios y debates políticos de la historia de Europa.

\section{Caracterización de la paradoja de la individualidad}

Para la definición de la paradoja que subyace al concepto de "individuo", seguiré la obra de Joan W. Scott, una de las primeras teóricas en tratar este problema. Para Scott (2012:22ss.), la palabra "individuo" tiene dos significados ambiguos y difícilmente compatibles, que coexisten en una relación tensa. La primera acepción es el prototipo abstracto de lo humano, "esencia común de toda la humanidad" (2012:23), que borra cualquier consideración diferencial o idiosincrásica en nombre de una idea universal, formal e igualitaria de individualidad. Todos seríamos individuos iguales en tanto que seres únicos y sin propiedades ni atributos. Se podría explicar esta idea con una noción leibniziana: cada individuo sería una mónada, un ser único y entero, sin partes ni relación con nada exterior, igual a todos los demás (2001:\$1-2). La segunda acepción que destaca Scott (2012:22) es la identitaria y diferencial. En este sentido, cada individuo sería un ser único en sí, una persona distinta a todas las demás de las otras de la especie y en relación diferencial con ellas. Para esta segunda acepción, ser uno significaría no ser otro. Por seguir explicando esta idea con Leibniz, cabría decir que, si todos los individuos fueran iguales en sus rasgos y características, entonces ya no se podrían distinguir entre sí, por lo que no podría saberse si se trata de un único ser o de varios. Por este motivo, ser individuo también significa ser diferente y diferenciable de los demás (2001:\$ 8-9). 
Situaré estos dos significados del término "individuo" en el terreno de la política, siguiendo a Scott, para mostrar el alcance y las consecuencias de la paradoja. En teoría política (sobre todo en declaraciones de derechos, de principios y de textos constitucionales), la noción de individuo más usada es la primera, la abstracta y formal. Scott (2012:23) sostiene que la primera aparición de este uso se dio en la Declaración de Derechos del Hombre y el Ciudadano de la Francia Revolucionaria de 1789: para lograr la universalidad de derechos y la eliminación de todos los privilegios, había que proyectar una noción de individuo abstracta donde no hubiera lugar para ningún tipo de diferencia ni social, ni física, ni corporal; ni "de familia, riqueza, ocupación, propiedad o religión” (2012:23). Al eliminar cualquier tipo de diferencia, todos seríamos iguales en tanto individuos, lo que legitimaría un mismo trato ante la ley, con pretensión de universalidad. Este es el sentido de expresiones como "Todos somos iguales ante la ley" o de contenidos como el artículo segundo de la Declaración Universal de Derechos Humanos, que mantiene que "toda persona tiene todos los derechos y libertades proclamados en esta Declaración, sin distinción alguna de raza, color, sexo, idioma, religión, opinión política o de cualquier otra índole, origen nacional o social, posición económica, nacimiento o cualquier otra condición” (1948:\$2). Esta concepción del individuo también se encuentra en la filosofía y la teoría política, desde la Modernidad, en expresiones como la de Bentham (citada por Stuart Mill, 1969:257, traducción de I.G.), según la cual "cada uno tiene que contar por uno, nadie por más de uno"; y ha encontrado una de sus definiciones más claras de la filosofía política contemporánea en la propuesta del velo de la ignorancia de John Rawls (1979:135ss.). Para este autor, la mejor forma de definir principios justos en una sociedad sería abstraer todos nuestros rasgos diferenciales para que fuéramos, de forma hipotética y orientativa, individuos abstractos, perfectamente iguales. Y también está presente en la obra de autores republicanos como Pettit, quien parte del que denomina "principio inclusivista", según el cual "todos los individuos tienen que contar por uno, y ninguno por más de uno"; por lo que todos deben ser tratados como individuos iguales (1999:149).

La segunda acepción es la diferencial. En este caso, se sostiene que para que un individuo sea reconocible e identificable como tal debe tener unos rasgos propios que lo diferencien de otros individuos. Scott encuentra una de las primeras formulaciones de esta idea en la Enciclopedia Francesa, donde se define "individuo" de esta manera: "Pedro es un hombre, Pablo es un hombre, pertenecen a la misma especie; sin embargo, se distinguen uno de otro por sus diferencias numerables. Uno es apuesto, el otro es feo; uno es culto, el otro es ignorante y cada uno de ellos es etimológicamente un individuo, porque no es posible dividirlo en nuevos sujetos que tengan existencia independiente. La combinación de sus rasgos es tal que, tomados 
en conjunto, no podrían aplicarse más que a él”. (Enciclopedia, Vol. 8, 1765; citada por Scott, 2012:22).

Según esta segunda comprensión, cada individuo ha de tener unos rasgos propios e inherentes, que lo diferencien de otros individuos o, incluso, de otros seres que ya no serían considerados como individuos. Scott (2012:23) destaca así cómo esta delimitación de características propias comienza siendo diferencial (Pablo y Pedro son diferentes, según el ejemplo de la Enciclopedia, aunque ambos sean individuos); pero, poco a poco, en la traducción de un concepto a la práctica política y la creación de leyes, esta delimitación se fue haciendo excluyente, dejando fuera a personas que no eran consideradas individuos (extendiendo el ejemplo anterior, se podría mantener que Fátima y su bebé de pocos meses no serían considerados individuos, ni iguales a Pablo y Pedro). Esto es, para que se comprenda el sentido mismo de "individuo" parece necesario un contraste con todo aquello que no lo sea, lo que, en el terreno político y de derechos en el que nos movemos, se traduce en la exclusión de personas que no son consideradas individuos, por lo que se perdería así la primera noción (la formal y universal) y, de este modo, sus dos sentidos serían incompatibles entre sí.

La paradoja surge por la incompatibilidad entre estas dos acepciones: la primera es abstracta, formal y universal; la segunda es concreta, particular y diferencial. ¿Cómo conjugar estas dos características opuestas (mismidad y diferencia) en un mismo concepto? Y especialmente (y aquí la dificultad ya no es solo teórico-epistemológica, sino que se torna política), ¿cómo establecer esta diferencia cuando se trata de responder a la pregunta sobre quién es individuo y sujeto de derecho?

Desde la aparición de los primeros estados modernos y constitucionales, quienes legislan y formulan derechos se encuentran ante una difícil situación: no siendo posible establecer un estado sin que haya una delimitación fronteriza y de identidad nacional (o ciudadanía), hay que estipular quién es reconocido como ciudadano y sujeto de derecho y quién no. Este es el problema del exterior constitutivo, concepto que Mouffe (2000:21) atribuye a Derrida. ${ }^{1}$ Esto es, pese a la pretensión de universalidad de textos como la Declaración de Derechos del Hombre y el Ciudadano (que presenta el primer sentido de individualidad, el abstracto); en realidad, no se puede dar la ciudadanía a todas las personas, sino que hay que establecer una diferencia entre el "nosotros nacional" y los otros, extranjeros o habitantes del mismo

\footnotetext{
${ }^{1}$ Sostengo que Mouffe atribuye la formulación de este problema a Derrida porque así lo hace, sin citarlo directamente. Más adelante esta autora desarrolla este problema siguiendo el libro de Henry Staten Wittgenstein and Derrida. Busqué en este libro y encontré una explicación similar a la que acabo de dar, atribuida asimismo a Derrida (Staten, 1984:17-18), pero la expresión concreta de "exterior constitutivo" no aparece en ese libro. Staten, a su vez, mantiene que esta idea aparece en Fuerza de ley, de Derrida, también la he consultado, sin encontrar esta denominación.
} 
estado nación, pero con menos derechos y obligaciones. Algunos de los primeros diputados de la Asamblea Nacional Francesa, como Mirabeau y Maubet, señalaron esta difícil decisión como un potencial desencadenante de conflictos y malestares en los primeros momentos de la Revolución Francesa, al no poder estar todas las personas incluidas como sujeto de derecho de la futura constitución (Scott, 2012:39).

En este sentido, los dos sentidos del término "individuo" presentan problemas y dificultades, en el momento en que se intenta responder a la cuestión de quién tiene ciudadanía. Mientras que el abstracto y universal no se puede trasladar a la realización efectiva del estado y la definición de sus leyes; el diferencial corre el riesgo de ser excluyente y quitar derechos a muchas personas.

A continuación, describiré varios intentos de aplicación y puesta en práctica de esta noción de "individuo" en distintos momentos de la historia europea y colonial, que suponen distintas respuestas a la pregunta sobre quién es sujeto de derecho, y motivan distintas críticas antirracistas, decoloniales y feministas. La pregunta que me guía en este análisis es qué sucede cuando se aterriza y se traslada a cuerpos de personas distintas esta noción paradójica de individualidad y quién queda fuera de esta noción (pretendidamente universal) cuando se pone en práctica.

\section{Poniendo cuerpo a la paradoja}

\subsection{La Francia revolucionaria y los derechos del ciudadano}

En el caso concreto del Estado francés postrevolucionario, la dificultad de delimitar quién era individuo se fraguó a lo largo de los dos años que se sucedieron desde la Toma de la Bastilla en julio de 1789 hasta el primer texto constitucional de 1791. $\mathrm{Al}$ acabarse con los privilegios de la monarquía y la aristocracia, y declararse que todos los seres humanos eran iguales ante la ley, se inauguró un nuevo régimen donde cualquier persona (con independencia de su procedencia, clase, sexo o raza...) podía, potencialmente, ser reconocida como individuo y sujeto de derecho. Ahora bien, en la codificación de esa posibilidad en el texto constitucional, fue necesario delimitar quién tendría derechos y ciudadanía y quién no, y ahí se abrió un amplio debate constitucional.

Como se puede leer en el título mismo de la Declaración de derechos del hombre y del ciudadano (Déclaration des Droits de l'Homme et du Citoyen), 1789, la redacción de este texto fundacional era en masculino y el sujeto poseedor de derechos era el hombre (homme), es decir, el varón exclusivamente. No se trata de un uso genérico del sustantivo, podría haberse utilizado el término "ser humano" (être humain) o 
podría haberse duplicado el sujeto, para incluir a hombres y mujeres; al contrario, hubo una postura manifiesta, y bastante unánime, para excluir a las mujeres, tanto de este texto, como de la ciudadanía. Esta exclusión llevó a Olympe de Gouges a redactar la Declaración de derechos de la mujer y la ciudadana (1791/1993), paralela a la oficial, en la que recordaba a los revolucionarios franceses que las mujeres también habían sido parte de la Revolución y merecían los mismos derechos de ciudadanía que ellos. Este debate llegó a la Asamblea Constituyente Francesa (Scott, 2012:57). Allí, unos pocos diputados, como Camille Desmoulins, apoyaron la propuesta de Olympe de Gouges y sostuvieron que había que otorgar la ciudadanía activa a cualquiera que hubiera participado en la Toma de la Bastilla (incluyendo a las mujeres y dejando fuera a quienes no apoyaron la Revolución, pero también a quienes eran demasiado mayores o enfermos para estar en la Toma). Por el contrario, la mayor parte de la Asamblea entendió que para tener la ciudadanía activa había que ser "individuo" e incluyeron en este término una noción diferencial, propia del segundo sentido explicado. Ser individuo ya no sería ser abstracto e igual a los demás, sino tener autosuficiencia y autonomía, ser dueño de uno mismo, poder hablar por uno mismo y tener la solvencia económica para no depender de nadie más (Scott, 2012:39). De esta forma, no se concedería ciudadanía ni derechos como el sufragio a todas aquellas personas que no tenían forma de mantenerse a sí mismas (por no tener tierras ni capital), y también quedaban excluidas las mujeres, por una consideración naturalista, mantenida sobre todo por los diputados jacobinos (Scott, 2012:73-74), según la cual, las mujeres, por su sexo, eran más débiles y dependientes que los varones y no podían ser ciudadanas; sino que su tarea era la crianza de nuevos revolucionarios y el cuidado del hogar.

La paradoja se ve con claridad en el primer texto constitucional de 1791 que declara, en su Preámbulo (1791), que ya no habría más diferencias ni privilegios por nacimiento, pertenencia a nobleza, herencia, ni privilegios de ningún tipo. Literalmente, no habría "ni para ninguna de la Nación, ni para ningún individuo, ningún privilegio ni excepción en el derecho común de todos los franceses" ${ }^{2}$ (Asamblea Nacional Francesa, 1791, Preámbulo, Traducción de I.G.).

Tras esta formulación universalista, donde se emplea el término "individuo" en el primer sentido de los dos explicados anteriormente: el abstracto y general, referido a todos los seres humanos (al menos los de nacionalidad francesa); en el desarrollo del texto constitucional el concepto de individuo se transformó en el segundo sentido: el diferencial y referido a una forma concreta de ser (masculina y con

\footnotetext{
${ }^{2}$ En su versión original: "Il n’y a plus, pour aucune partie de la Nation, ni pour aucun individu, aucun privilège, ni exception au droit commun de tous les Français".
} 
propiedades), que ya no es universalizable. En este caso, se entiende que solo son individuos, $y$, por tanto, poseedores de derecho, los varones, mayores de veinticinco años y que no estén en un estado de dependencia doméstica o al servicio de nadie ("état de domesticité, c'est-à-dire de serviteur à gages", Asamblea Nacional Francesa, 1791:II, 2). La ciudadanía activa (con todos sus derechos de participación) solo se daría a varones nacidos en Francia, hijos de padre francés (no se menciona la nacionalidad de la madre) o a extranjeros (siempre varones) que llevaran más de cinco años residiendo en el país y hubieran realizado el juramento cívico de compromiso con la nación (1791:I, 2). En este caso, se indica que se concederá la ciudadanía a aquellos extranjeros "que adquieran inmuebles o se casen con una mujer francesa" (“acquis des immeubles ou épousé une Française”, 1791:I, 3). De este modo, las mujeres francesas no solo habían dejado de ser consideradas como sujeto (político), al quedar equiparadas con un objeto o inmueble; sino que adquirieron la paradójica capacidad de otorgar ciudadanía a extranjeros, vía matrimonio, pese a que ellas mismas no fueran ciudadanas.

Incluso en textos posteriores, clásicos como el de Michelet, de 1854, se relata que las mujeres fueron parte de la Revolución Francesa, pero no como sujeto político con derechos, sino como madres de héroes revolucionarios (2010:15), o como seres benignos y piadosos, que denunciaron los abusos del Antiguo Régimen (2010:19ss.). Michelet no deja de emplear argumentos naturalistas para describir a las mujeres como pobres víctimas indefensas de los acontecimientos revolucionarios: seres "nacidos para vivir en unión con otro" (2010:34), que no son "nada sin la familia" y quedaron debilitadas, "huérfanas, desconsoladas [...], sin protección", en la miseria y hambruna de la Francia de 1789. Fue el hambre y su "gran corazón" compasivo los que hicieron que las mujeres ocuparan las calles de París en 1789, apoyando así a la Revolución (2010:36).

En definitiva, solo en contados y excepcionales casos (como el de Olympe de Gouges, que murió guillotinada por sus ideas y su reivindicación de ser tratada como una ciudadana igual) las mujeres fueron reconocidas como individuos, sujeto de derechos y participantes activas en la Francia revolucionaria. En realidad, quedaron encuadradas en aquello que Benhabib (2002:171ss.) denomina el "otro generalizado": una forma de ser no individualizada, prototípica de personas débiles y dependientes (como bebés, personas enfermas, ancianas y mujeres) que, al no ser autónomas ni poder cuidarse por sí mismas, han de quedar resguardadas en lo privado, en el hogar. Esta forma de ser se opone al "otro concreto": individuo diferenciado y varón, que es el único que puede ser considerado como ciudadano en sentido pleno y desarrolla su actividad en la esfera pública. Mientras que las virtudes características del otro generalizado son éticas, como la piedad, el cuida- 
do y la compasión; las del otro concreto son políticas, relacionadas con la justicia y el derecho.

Merece la pena volver a traer a colación en este momento la crítica de Scott, según la cual, el concepto, aparentemente abstracto y universal, de "individuo" se acabó convirtiendo, en la Francia revolucionaria, en sinónimo de varón y propietario, en relación diferencial y restrictiva con las mujeres, los varones de color y los esclavos, que veían restringidos sus derechos. En palabras de Scott: "El individuo universal que ejercía los derechos políticos del 'hombre' es a la vez abstracto y concreto" (2012:28, comillas sencillas suyas). Asimismo, es importante recordar que este veto a los derechos de ciudadanía de las mujeres en Francia se mantuvo, en la ley, hasta 1944 cuando por fin les concedieron el derecho al voto (2012:18).

Scott critica así esta comprensión de la individualidad en la Francia revolucionaria, por su "definición universal y encarnación masculina" (2012:29). Además, yo también añadiría "encarnación blanca", ya que, aunque a partir de 1794 se abolió la esclavitud en Francia y se otorgó la ciudadanía a varones de color, residentes en las colonias; en realidad y en la práctica siguió habiendo una consideración diferencial entre ciudadanos franceses blancos, residentes en el continente, y ciudadanos franceses de color, residentes en las colonias o excolonias. Este trato diferencial continuó hasta el siglo XX, como explicaré en el siguiente apartado, siguiendo a Fanon y a Charles Mills.

\subsection{Fanon y Mills: la individualidad blanca y todos los otros}

Para el teórico francés nacido en Martinica, Frantz Fanon, en la definición del concepto de ser humano (que yo voy a equiparar a individuo por lo que explicaré a continuación) se daba una dificultad semejante (y sin duda heredera) de la que destacó Scott en referencia al sujeto revolucionario francés. Según Fanon, "el hombre negro no era humano" (2009:42), ${ }^{3}$ porque la "única posibilidad de ser humano, el único reconocimiento como tal, era en el caso de ser blanco" (2009:44), lo que era imposible para personas con piel de otro color. En su narración en primera persona Fanon mantiene que: "yo quería simplemente ser un hombre entre otros hombres. Hubiera querido ser igual [...], y el mundo blanco, el único honrado, me negaba toda participación" (2009:113-114).

\footnotetext{
${ }^{3}$ En otra muestra de la paradoja y todas sus aristas, Fanon usa literalmente el término hombre (homme en el original) para referirse, de modo genérico, a lo humano; dando por supuesto que sus reivindicaciones por el reconocimiento de las personas negras valían igualmente para hombres y mujeres. En este sentido, autoras como Arruzza (2015) y Rowbotham (1973), respectivamente, han criticado el machismo existente en grupos de izquierda y antirracistas. No continuaré con esta crítica porque extendería demasiado este texto.
} 
Como vimos anteriormente, en la paradoja inherente al concepto de "individuo" siempre se daban dos posibilidades incompatibles, que contrastan con la realidad física de quien es diferente, ya sea por su sexo (como en el caso de las mujeres en la Francia revolucionaria), ya sea por su color de piel (como en la denuncia de Fanon). Si nos acercamos al polo más abstracto, cualquier rasgo diferencial (sexo, color de piel...) no sería considerado como relevante, al presuponerse que todos los individuos han de ser tratados como iguales, sin distinción ni atención al detalle, en lo que José Medina ha denominado "ceguera epistémica a la diferencia" (2012:149). Esto es, en su pretensión de abstracción y pureza, esta comprensión no puede llegar a diagnosticar, ni comprender las dificultades de algunos sectores de la población: los que menos se asemejan al sujeto hegemónico de derecho (blancos, europeos, varones). Aparece así el segundo polo del concepto de individuo ya explicado: el diferencial. Ya sea por haber nacido con un sexo determinado, ya sea por el color de la piel o por el nivel socioeconómico, hay personas que no son consideradas como individuos y, por ello, pierden derechos, reconocimiento y se enfrentan a dificultades constantes; lo que, de nuevo, bloquea la pretensión de universalidad de la noción política de individuo.

Fanon reconoce esta paradoja y la desarrolla en su propia experiencia, en sus intentos de ser reconocido como un individuo, igual y ciudadano, por los hombres blancos. Siendo, por nacimiento y por ley, ciudadano francés, encontraba dificultades constantes y falta de reconocimiento y de legitimidad cuando se mudó, desde su Martinica natal, a París. Se encuentra entonces ante dos posibilidades de acción: o bien, "sostener el mundo blanco, es decir, el 'verdadero mundo' y así, empleando el francés, plantear algunos problemas y tender en sus conclusiones a un cierto grado de universalismo"; o bien, "rechazar Europa, [...], y agruparse en el dialecto, instalarse [...] en el 'Umwelt martinicano"' (2009:62, comillas sencillas del autor).

Es decir, si quería ser aceptado como un igual, reconocido como individuo y que sus palabras fueran escuchadas y consideradas, entonces Fanon debía abandonar su adscripción martinicana, su forma de hablar y de vestir, su acento, su origen, para acercarse a ese "verdadero mundo" (francés, blanco, con correcto acento y trajes europeos). Ahora bien, esa opción significaba negar gran parte de su identidad y sus raíces, y, en cualquier caso, no podía cambiar su aspecto, su color de piel, por lo que nunca sería considerado ni como un individuo ni como un igual. La segunda opción tampoco era más conveniente: rechazar Europa y su (pretendido) universalismo, le llevaría a un gueto identitario, a solo relacionarse con los suyos y quedar circunscrito a una forma diferencial de ser, racializada y grupal, cerrada. Por este motivo, no entraría nunca en la categoría de individuo. 
Sin embargo, Fanon destaca que ninguna de estas dos posibilidades le funcionó: en un mundo racista y colonizado, como el suyo (y el nuestro), asegura que "no es posible hablar de identidad" para personas como él (2009:111). También mantiene que ni la filosofía, ni la ontología (ni, cabría añadir, cualquier intento de comprensión abstracta de la individualidad) permiten "comprender el ser del negro" (2009:111). El ser negro (al igual que el ser mujer) solo tiene sentido y significado como una adscripción particular y diferenciada del caso más general: el ser blanco. Vuelve a aparecer aquí la dificultad del segundo sentido de "individuo": para que este término tenga sentido debe poseer ciertas características diferenciales (la blanquitud en este caso) que excluyen de la individualidad a quien no posea estos rasgos. Por este motivo, las personas negras nunca serán consideradas como individuos, sino como otros e inferiores. Los negros, continúa Fanon, solo "han tenido dos sistemas de referencia en relación a los cuales han debido situarse": por un lado, el blanco universal, que nunca los aceptará como iguales y los discriminará; por otro lado, sus costumbres y tradiciones propias, que los circunscriben en el ámbito de "lo otro", negándoles individualidad y derechos; y que, al final, "fueron abolidas porque contradecían a la civilización [blanca] que se les imponía" (2009:111).

En ese momento, sin tradición propia ni posibilidad de participación en el mundo blanco, estos sujetos otros se convierten en objetos, observados, juzgados y denostados por los blancos: "Y entonces nos fue dado el afrontar la mirada blanca" (2009:112). "Las miradas blancas, las únicas verdaderas, me disecan. Estoy fijado. Una vez acomodado en su microscopio, realizan los cortes de mi realidad. Soy traicionado. Siento, veo en esas miradas blancas que no ha entrado un hombre [...], sino un negro" (2009:115).

Fanon vive, en su propia experiencia, la paradoja que estoy desarrollando desde el inicio de este artículo y la describe como un "círculo infernal" (2009:116), del que no puede salir y que solo le genera "vergüenza y desprecio hacia mí mismo" (ib.). No hay salida para las personas de color en un contexto colonial y poscolonial donde siempre van a ser vistas como negras, nunca como individuos: "Cuando se me quiere, se me dice que es pese a mi color. Cuando se me odia, se añade que no es por mi color" (2009:116). De esta forma, Fanon mantiene que "sin pasado negro, sin futuro negro, me es imposible vivir mi negritud. ${ }^{4}$ Aún no blanco, para nada negro, solo puedo ser un condenado" (2009:130).

En una línea similar, el teórico Charles Mills (1998) ha destacado un aspecto más de este mismo efecto paradójico, y en última instancia, difícilmente soportable, para gran parte de la población racializada. El conflicto se da, según este autor

${ }^{4}$ Aunque el traductor puso "negrez", he preferido traducir "négritude" por "negritud". 
(1998:7-8), por la dominación intelectual y legal de quienes están en posición de poder y saber (legisladores y teóricos blancos). Este sector particular y privilegiado de la población entiende como universales sus categorías, dejando fuera, sin reconocimiento, a quienes son diferentes (por su sexo, su color de piel, su acento, su nacionalidad o la falta de ella...). De esta manera, los sujetos otros, los no reconocidos, ni universalizables, interiorizan su malestar en una suerte de "escepticismo del yo" (1998:8, Traducción de I.G.). Estos sujetos otros sienten dudas constantes sobre su propia identidad, sobre si son personas reales, individuos, merecedoras de respeto y derechos; o si, por el contrario, son personas de "segunda categoría", menos individuos que merecen el trato degradante recibido. Es decir, la paradoja ya no se da solo en los textos políticos y declaraciones de derechos, sino que se traslada e instala dentro de los mismos cuerpos de estas personas que no solo no son reconocidas como individuos, ni sujetos de derecho; sino que ellas mismas tampoco se reconocen como tales. En última instancia, y según este argumento de Mills, estas personas aceptan la segunda acepción del término "individuo", la diferencial, y ellas mismas se autoexcluyen de esta categoría, llegando a pensar que no merecen aquello que sí merecerían si permaneciésemos en la primera acepción del concepto de individuo: la universal y formal.

Esta inseguridad vivida y esta exclusión de derechos básicos y universales no deja de estar relacionada con el pasado colonial y el presente decolonial europeo, en lo que Mignolo (2005) ha denominado la "herida colonial", y paso a describir, siguiendo a Sara Ahmed.

\subsection{La individualidad occidental y la cultura migrante según Abmed}

Situada en las sociedades europeas contemporáneas, de forma más concreta en Reino Unido, la filósofa británica-australiana, con raíces paquistaníes, Sara Ahmed da otra formulación a la paradoja de la individualidad, explicada en este artículo, en el contexto de los debates sobre la integración (o no integración) de migrantes en países europeos. Ahmed analiza discursos políticos, de medios de comunicación y documentos y planes para favorecer la integración de migrantes en Reino Unido y encuentra en ellos un contraste entre lo que se entiende como "culturas de migrantes" (tradicionales, con restricción de libertades y no individualizadas), y la "civilización occidental", que no se describe en términos de cultura (esto es, de grupo o colectivo), sino de posibilidades, trayectorias y libertades individuales. En estos textos dirigidos a migrantes en Reino Unido para fomentar su "integración" se promete que, una vez se liberen de su cultura migrante y de sus tradiciones, 
cualquiera va a poder ser individuo, libre y elegir su propio destino. Ahmed critica así que en estos programas y discursos solo aparezca definida como cultura (esto es como algo colectivo, ya dado o que se posee y que no se puede modificar) la "cultura migrante", que contrasta con el concepto vacío y sin atributos ni características del "individualismo occidental, donde las personas tienen la libertad de ser lo que quieran” (2019:275).

Así, del mismo modo que la noción abstracta de individuo (la primera de las descritas) se definía como universal y vacía, Ahmed destaca cómo la forma de vida occidental se presenta como neutra y sin mandatos ni obligaciones, no debida a ninguna tradición u obligación, más allá del respeto de las leyes de cada país, que son las que conceden ciudadanía. Esta forma de vida de Occidente no se comprende como cultura ni tradición porque, aparentemente, no tiene contenido; solo promueve las libertades individuales, el desarrollo libre de cada individuo y propone, en una suerte de fantasía neoliberal, que, si cada persona se lo propone y se esfuerza lo suficiente podrá llegar a ser lo que desee (2019:275).

De esta forma, el migrante recién llegado a Europa y también sus descendientes (aquí Ahmed se refiere a su propia experiencia, como hija de paquistaní) se ve ante un dilema, no tan distinto al formulado por Fanon y descrito en el apartado anterior: o escoger la libertad y devenir individuo; o permanecer en la tradición, el deber, seguir en el grupo no integrado y no ser reconocida como individuo. Solo la primera opción conlleva la posibilidad de abrazar la identidad nacional y de "aproximarse a la blanquitud"s (2019:277). Se trata de una forma de "dejar atrás un mundo" y "unas costumbres que atan" para ascender o moverse hacia adelante, alejarse de la tradición. Esta es la única posibilidad de convertirse en individuo y ciudadano nacional, con todos sus derechos y libertades reconocidos (2019:279). En palabras de Ahmed: "Al volverse individuo, se adquiere el sentido de la libertad: se adquieren capacidades, energías, proyectos propios. A su vez, estas capacidades, energías y proyectos se convierten en un signo de que la libertad es buena" y de que el estado-nación da las mismas oportunidades a todos (2019:280). En el lado opuesto del dilema estaría quien se niega o no logra abandonar sus costumbres. Esta persona queda "fuera de lugar", no adaptada y presa de su tradición (2019:301), por lo que no estaría integrada en la sociedad y siempre sería tratada como alguien externo, extranjero, diferente e incluso sospechoso.

Ahora bien, esta búsqueda de la individualidad y de la libre trayectoria conlleva un precio: la pérdida de raíces y el debilitamiento de comunidades afectivas (2019:311).

\footnotetext{
5 El término que usa Ahmed en el original es "whiteness", la traductora puso "blanquedad", yo he optado por "blanquitud", que es el término que he usado a lo largo de todo el artículo.
} 
La persona "integrada" habría abandonado su tradición y su raíz, para ser (aparentemente) un individuo de pleno derecho, igual e indistinguible de otros (de forma similar a la primera acepción de individuo); pero carecería de conexión, de red de apoyo en una tradición, grupo o comunidad que le sostenga, cuide y provea. De esta manera, llegar a ser individuo bien adaptado también significa perder la raíz.

Destaca Ahmed, por último (2019:312), el racismo implícito que subyace a este discurso y en esta idea de "individualidad", que es problemática, en tanto se presenta como neutra y vacía, pero posee ciertos contenidos, muy concretos, no solo legales sino también identitarios, que resultan difíciles de seguir para alguien que ha migrado al país. En este sentido y siguiendo la línea de críticas que abre este artículo, cabría preguntar si la individualidad occidental es tan abstracta, formal y vacía como parece

o si, por el contrario, acaso no presenta ciertos contenidos, ya no solo ciudadanos y legales (en el sentido de cumplir la ley, tener derechos, libertades y obligaciones) o propios de la noción de autonomía con la que está relacionada la individualidad desde la Revolución Francesa (es individuo quien se puede mantener a sí mismo); sino también (y aquí aparecen los problemas políticos) si acaso "estar integrado" y "ser individuo" no significa tener "identidad británica" (por ejemplo, entender las normas del críquet, seguir al Manchester United o al Liverpool, y tener unos ciertos hábitos alimenticios como desayunar huevos benedictinos, comer fish and chips o reunirse con la familia los domingos para comer asados y pudines, mashed potatoes and gravy). Lejos de ser anecdótico, algo tan material como preferir comer pollo tikka masala a Yorkshire pudding ya puede significar ser reconocido como persona integrada o no y, por lo tanto, ser más o menos individuo y poder tener o no derechos y ciudadanía.

Por último, no hay que olvidar que el hecho de no ser reconocido como un individuo integrado en el país conlleva, como ya hemos visto, la culpabilización, sospecha e incluso criminalización de quien no se adapta, de quien es diferente. Para Ahmed (2015:114ss.), la idea de individuo legitima ciertas formas de ser y de estar en el espacio; y culpabiliza o criminaliza a otras, instalando el miedo ante quien es diferente y limitando los derechos y libertades de quien es diferente. La autora no deja de ver en este hecho el carácter excepcional y frágil de esta idea de individuo, que no se sostiene ante formas de vida distintas a las de Occidente y que revela, de nuevo, lo difícil que es transitar esta noción de individuo, abstracta y diferencial a la vez.

\section{Algo así como una conclusión para una paradoja sin cierre}

Mientras escribo este artículo, en septiembre de 2021, comienza el debate electoral para la presidencia de Francia y Marine Le Pen (2021), candidata por el partido 
ultraderechista Rassemblement National [Agrupación Nacional] propone un referéndum para cambiar la Constitución francesa y dar "prioridad nacional" en materia de derechos a las personas de nacionalidad francesa sobre los extranjeros. Le Pen plantea, además, fortalecer y blindar la Constitución Francesa para que tenga preeminencia sobre cualquier texto internacional de protección de los derechos humanos. Vemos así, en pleno siglo XXI y en la muy democrática y republicana Francia, cuna de los derechos del hombre y el ciudadano, una muestra más de la problemática que he intentado presentar a lo largo de este artículo.

Más allá de que las declaraciones de Le Pen sean una proclama electoral de difícil realización, en su propuesta aparecen, de nuevo, las dobleces del concepto de individuo como sujeto de derecho. En este caso ha desaparecido, por completo, la noción abstracta neutra y con pretensión de universalidad del concepto de individuo y, en el racismo y nacionalismo de esta candidata, esta noción se hace diferencial y excluyente (segunda acepción) y queda restringida al individuo de nacionalidad francesa (ya sea hombre o mujer). De esta manera, se excluye de un concepto, en principio universal, a cualquier otra persona que no cumpla con este criterio de nacionalidad y, cabría pensar (aunque Le Pen no lo diga) que tampoco se admitiría a nadie que no cumpliera el criterio de blanquitud y buena adaptación al prototipo de buen ciudadano francés, como criticó Ahmed (2019) en el caso de la ciudadanía británica y vimos en el apartado anterior.

Sin embargo, la exclusión de muchas personas del concepto de individuo que hace Le Pen se diferencia de la que hacían los primeros revolucionarios franceses en que ella restringe y limita, a propósito y con una clara agenda ultraderechista y neoliberal, el concepto de individuo; mientras que estos revolucionarios empezaban apenas a dirimir cuestiones de derecho, estando todavía presos de unas nociones naturalistas sobre las diferencias entre los sexos y las razas que hoy (al menos desde la Declaración Universal de Derechos Humanos de 1948) no resultan admisibles.

Entonces, aunque a lo largo de este artículo he criticado el carácter abstracto y vacío de la primera noción de individuo por ser irrealizable; la segunda posibilidad (diferencial y restrictiva) se revela ahora mismo (con el ascenso de la ultraderecha, racista y misógina) como una posibilidad real, profundamente injusta y discriminadora, que contradice todos los principios y declaraciones universales de derechos (abstractas e irrealizables, pero necesarias). Vuelve a aparecer aquí la dificultad del segundo sentido de "individuo", con todas sus consecuencias violentas y excluyentes, vividas y sufridas especialmente por quienes no llegan a cumplir los requisitos necesarios para ser reconocidos como individuos por su sexo, género, nacionalidad, color de piel o cualquier otro rasgo diferencial. Ante esta exclusión y vulneración de derechos, y normalización de discursos racistas y misóginos de la extrema dere- 
cha, que niegan y reducen, cada vez más, el concepto de individuo como sujeto de derechos, para que solo incluya a quienes son iguales a ellos, considero más importante que nunca volver a reivindicar el primer sentido de "individuo": el universal y formal.

Esta noción de individuo abstracta y universal es algo que, como diría Wendy Brown (citando a Spivak) "no podemos no querer" (2020:245). Sin embargo, no podemos no querer cualquier concepto de individuo, específicamente, y viendo este auge de la ultraderecha y del neoliberalismo, no voy a reivindicar el concepto de individuo aislado, desconectado y despolitizado, personificado en el homo economicus, que se viene promulgando desde el neoliberalismo y que, como mantiene Brown (2019), acaba siendo antidemocrático y excluyente. La noción de individuo que no podemos no querer es heredera de la noción republicana y revolucionaria francesa que vinculó, por primera vez en la historia, los conceptos de individualidad, sujeto de derechos y universalidad. Además, como por ejemplo mantiene Darat (2021), es necesario entender que la autonomía individual no supone que seamos un ser aislado en el mundo, adulto y autosuficiente (una mónada, cabría decir); sino que también entraña dependencia a otros seres humanos y el reconocimiento de nuestra vulnerabilidad. Si unimos el concepto de individuo de la tradición republicana, como sujeto de derecho y pretensión de universalidad, con el reconocimiento de la vulnerabilidad humana y nuestra mutua dependencia, nos encontramos con la forma de ser individuo que no podemos no querer.

Es decir, aunque conviene contextualizarla, ponerle cuerpo y vincularla a nuestra vulnerabilidad común, la noción abstracta y con pretensión de universalidad de la noción de individuo que empezó a fraguarse en la Francia de finales del siglo XVIII y que alcanzó su forma y definición más concreta en las distintas declaraciones de los Derechos Humanos de mediados del siglo XX es (incluso siendo deficitaria, muy problemática y potencialmente excluyente) una conquista a la que no podemos renunciar, especialmente en este momento cuando los Derechos Humanos están siendo amenazados por el avance de una ultraderecha racista y misógina que no esconde su intención de abandonar la pretensión de universalidad, para restringir el concepto de individuo a una élite privilegiada, igual a sí misma, dejando a todos los demás fuera. 


\section{REFERENCIAS BibLIOGRÁFICAS}

Ahmed, S. (2015). La politica cultural de las emociones. UNAM.

Ahmed, S. (2019). La promesa de la felicidad. Caja Negra.

Arruzza, C. (2015). Las sin parte. Matrimonios y divorcios entre feminismo y marxismo. Sylone.

Asamblea Nacional Francesa (1789). Déclaration des Droits de l'Homme et du Citoyen. Conseil Constitutionnel Français. (https://www.conseil-constitutionnel. fr/le-bloc-de-constitutionnalite/declaration-des-droits-de-l-homme-et-du-citoyen-de-1789).

Asamblea Nacional Francesa (1791). Constitution 1791. Conseil Constitutionnel Français (https://www.conseil-constitutionnel.fr/les-constitutions-dans-l-histoire/constitution-de-1791).

Benhabib, S. (2002). El ser y el otro en la ética contemporánea. Gedisa.

Birulés, F. (2015). Entreactos. En torno a la política, el feminismo y el pensamiento. Katz.

Brown, W. (2019). In the Ruins of Neoliberalism: The Rise of Anti-Democratic Politics in the West. Columbia UP.

Brown, W. (2020). Derechos como paradojas, Las Torres de Lucca. Revista Internacional de Filosofía Politica. Vol. 9, n 17. Julio - diciembre 2020 (pp. 243-261).

Darat, N. (2021). Autonomía y vulnerabilidad. La ética del cuidado como perspectiva crítica, Isegoría. Vol. 64, artículo 3 (pp. 1 - 11). DOI: https://doi. org/10.3989/isegoria.2021.64.03

De Gouges, O. (1993). Declaración de derechos de la mujer y la ciudadana, en A. Puleo (ed.) La Ilustración olvidada. La polémica de los sexos en el siglo XVIII. Anthropos. [Texto original de 1791].

Fanon, F. (2009). Piel negra, máscaras blancas. Akal.

Leibniz, G. W. (2001). Monadología. Biblioteca Nueva.

Le Pen, M. (2012). Présidentielle 2022, en France 2. 27 de septiembre de 2021 [vídeo] (https://www.francetvinfo.fr/elections/presidentielle/presidentielle2022-je-vais-gagner-cette-election-affirme-marine-le-pen-sur-le-plateau-defrance-2_4786567.html)

Medina, J. (2012). Epistemology of Resistance. Harvard UP. 
Michelet, J. (1854/2010). Mujeres de la revolución. Madrid: Trifaldi. [Texto original de 1854].

Mignolo, W. (2005). La idea de América Latina. La herida colonial y la opción decolonial. Gedisa.

Mill, J. S. (1969). Essays on Ethics. Collected Works. Vol. X. Routledge.

Mills, Ch. (1998). Blackness Visible: Essays on Philosophy and Race. Cornell UP.

Mouffe, Ch. (2000). The Democratic Paradox. Verso.

Pettit, Ph. (1999). Republicanismo. Una teoría sobre la libertad y el gobierno. Paidós.

Rawls, J. (1979). Teoría de la justicia. Fondo de Cultura Económica.

Rowbotham, Sh. (1973). Women, Resistance and Revolution. Allen Lane.

Scott, J. W. (2012). Las mujeres y los derechos del hombre. Siglo XXI.

Staten, H. (1984). Wittgenstein and Derrida. University of Nebraska Press.

UNESCO (1948). Declaración Universal de Derechos Humanos (https://www. un.org/es/about-us/universal-declaration-of-human-rights).

Wittgenstein, Ludwig (1988). Investigaciones Filosóficas. Crítica.

DOI: https://doi.org/10.15366/bp2021.28.007

Bajo Palabra. II Época. No28. Pgs: 155-174 
